HIV

\title{
Male clients of brothel prostitutes as a bridge for HIV infection between high risk and low risk groups of women in Senegal
}

\author{
M E Gomes do Espirito Santo, G D Etheredge
}

Sex Transm Infect 2005;81:342-344. doi: 10.1136/sti.2004.011940

\begin{abstract}
Objective: To explore the extent to which male clients of prostitutes have a role as a bridge in the spread of HIV into the general population of Dakar, Senegal.

Methods: A sexual behaviour HIV prevalence survey was carried out among clients of female prostitutes working in brothels recruited outside the prostitutes' rooms after the encounter. All men entering the house and leaving the women's rooms were asked to answer the questions and to donate saliva for HIV-1 and HIV-2 testing.

Results: Findings suggest that a proportion of clients form a potential bridge for HIV transmission between prostitutes and partners from the general population. They have unprotected sexual contacts with both brothel prostitutes, and steady and casual partners, and expose both unmarried and married women to HIV infection. Findings also indicate that wives are more exposed to HIV than other categories of women in the population.

Conclusions: Clients of brothels' prostitutes have a significant potential for spreading HIV beyond the initial high risk behaviour groups in Senegal. Efforts should be provided to target specific groups at higher risk for HIV infection, such as young men from the densely populated working class neighbourhoods of Dakar, and women outside the commercial sex networks for HIV education and prevention.
\end{abstract}

l

Africa, where heterosexual transmission accounts for the greatest proportion of HIV infection, many studies have shown high levels of HIV infection among people defined as prostitutes. ${ }^{12}$ In the absence of other known risky behaviours patterns, female prostitutes constitute the most important identified "core group" ${ }^{\prime 3}$ for HIV transmission in African countries. Theirs clients, a hard to reach population, may constitute another core group for HIV transmission ${ }^{4}$ : they have unprotected sexual contact with both prostitutes and women from the general population and so have a potential to spread HIV infection beyond the high risk groups. They constitute a so called "bridge population."

In Senegal, HIV prevalence in the general population is described to be still "low": In 2002, according to the surveillance system, the median HIV prevalence among women attending care clinics at 11 sites was $1.1 \% .^{5}$ For female prostitutes, however, the prevalence outside Dakar, the capital, was estimated to be $21.3 \%$, with the highest in Ziguinchor $(28.5 \%)$ in the south and Kaolack $(28.0 \%)$ in the centre of the country. In Dakar, the prevalence in female prostitutes was estimated to be $19.4 \%$. HIV prevalence in male clients of prostitutes in Senegal is unknown; nevertheless, prevalence of HIV in males attending STD clinics is estimated to be around 5\%. Data on HIV and AIDS in Senegal indicate that women are at increasing risk for HIV: the proportion of women among patients hospitalised for AIDS increased over the years, rising from $20 \%$ in 1986 to $45 \%$ in $1998 .^{6}$

Models have been proposed suggesting that the spread of HIV/AIDS is mainly the result of the sexual interaction between a core group of female prostitutes and young unmarried males ${ }^{7}$ and that an epidemic among prostitutes precedes the spread of HIV in the general population, ${ }^{8}$ after saturation of "high risk" behaviour groups.9 This second epidemic is dependent on the patterns of sexual mixing and bridging among groups.

Thus, in order to investigate this further, a study was undertaken among clients of prostitutes in seven brothels in Dakar, which aimed to explore the extent to which these male clients of prostitutes may act as a bridge and contribute to the spread of HIV to the general population.

\section{Some aspects of prostitution in Senegal}

In Senegal, prostitution (the exchange of sexual services for money or material goods) exists predominantly in urban centres. Prostitutes are generally well defined groups of women whose primary occupation is the sale of sex for money.

Prostitution has been legal in Senegal since 1970. The law makes it compulsory for any female prostitute older than 21 years to enrol in a health service. After enrolment, a health record is given to the woman and a medical follow up is conducted in specialised centres located in major cities. Free condoms are provided beginning at the first visit and are renewed monthly.

\section{MATERIALS AND METHODS}

A sexual behaviour HIV prevalence survey was carried out in seven brothels in Dakar among clients of female prostitutes. Brothels in Dakar are, roughly speaking, a group of one or two storey houses rudimentarily forming a compound, to which men come to buy sexual services from female prostitutes.

In order to obtain a representative sample of male clients of brothel prostitutes, a venue based probability survey method developed by the Centers for Disease Control and Prevention (CDC), combining outreach techniques with standard methods of survey sampling, was adopted. ${ }^{10}$ Brothels were randomly assigned to time slots and all clients entering the brothels during the time slots were solicited to participate in the study.

An inventory of the brothels in Dakar was established for the purpose of the study. From an initial listing and making repeat visits in the neighbourhoods of Dakar, a final list of seven brothels in five different neighbourhoods came up, with four brothels located in the two more densely populated neighbourhoods. 
Table 1 Sociodemographics characteristics and reported sex behaviour of clients according to their bridge category

\begin{tabular}{|c|c|c|c|c|}
\hline Characteristics & Bridge $(n=152)$ & Potential bridge $(n=395)$ & Non-bridge $(n=528)$ & p Value \\
\hline Median age & 25.0 & 25.0 & 24.0 & \\
\hline Mean age (range) & $26.04(24.9-27.1)$ & $26.12(25.4-26.8)$ & $25.3(24.8-25.8)$ & NS \\
\hline Senegalese nationality & $84.2 \%$ & $87.3 \%$ & $83.5 \%$ & NS \\
\hline No formal education & $43.7 \%$ & $43.7 \%$ & $60.3 \%$ & $<0.001$ \\
\hline Frequent several brothels & $46.4 \%$ & $24.2 \%$ & $23.2 \%$ & $<0.001$ \\
\hline Always buy sex from different women & $75.9 \%$ & $54.7 \%$ & $58.3 \%$ & $<0.001$ \\
\hline $\begin{array}{l}\text { Sex contacts with prostitutes previous } \\
7 \text { days } \geqslant 1\end{array}$ & $15.3 \%$ & $9.4 \%$ & $8.3 \%$ & 0.04 \\
\hline HIV status positive & $5.3 \%$ & $2.7 \%$ & $4.9 \%$ & NS \\
\hline$\geqslant 26$ years old & $10.1 \%$ & $5.2 \%$ & $7.2 \%$ & NS \\
\hline$\leqslant 25$ years old & $1.2 \%$ & $0.9 \%$ & $3.4 \%$ & NS \\
\hline $\begin{array}{l}\text { Had at least one STD during previous } \\
6 \text { months }\end{array}$ & $16.6 \%$ & $6.9 \%$ & $6.2 \%$ & $<0.001$ \\
\hline
\end{tabular}

In brothels, interviews took place in the yards within the compounds, from $7 \mathrm{pm}$ (opening hour) until the end of the activities. Clients were recruited outside the prostitutes' rooms after the encounter. They were informed of the study purpose and the dispositions for strict confidentiality.

Saliva sample collection and testing were performed using a kit from Saliva Diagnostics Systems (Medford, NY, USA), which contains a general purpose saliva collection device and a test strip for the detection of antibodies to HIV types 1 and $2 .^{11}$

Clients were classified in three groups according to their potential to form a bridge between prostitutes and women of the general population: (1) those reporting sex with steady partners and casual encounters and unprotected sexual relations with brothel prostitutes, (2) an intermediate category of men reporting steady partners and casual encounters but regular use of condoms with prostitutes, and (3) the remaining clients who reported sex only with prostitutes. These three groups were categorised respectively as bridge, potential bridge, and non-bridge.

Descriptive and inferential statistical analyses were performed with SPSS 10 and odds ratios were estimated with 95\% confidence intervals. Demographics and sex behaviour were compared between the three categories of clients. Logistic regression was used to explore the relations between significant predictors to bridge formation. All $p$ values reported are two sided and values were considered significant if $\mathrm{p}<0.05$.

\section{RESULTS}

From the 1450 men entering the brothels during fieldwork, $1140(79 \%)$ consented to answer the questions. Saliva samples for testing were obtained from 1083 (95\%) of the
1140 but 12 tests were invalidated. This analysis concerns sex behaviour of 1075 clients.

Among the $50.9 \%$ of clients who reported steady partners and casual encounters, $27.8 \%$ constituted the bridge population and $72.2 \%$ constituted the potential bridge. The remaining $49.1 \%$ clients formed the non-bridge population. Demographic characteristics and sexual behaviour of the three groups are compared in table 1. Clients in the bridge population changed brothels more often, had a higher frequency of sexual contacts with prostitutes, a higher rate of prostitute change, and reported more sexually transmitted infections (STI) during the previous 6 months. Additionally, clients in the non-bridge population mostly had no formal education. The three groups did not differ significantly on HIV status.

Using logistic regression analysis (table 2) clients classified as bridge and those classified as potential bridge differed essentially on frequency of brothel frequentation and rate of prostitute change. Between bridge and non-bridge clients, differences were observed on brothel frequentation but also on use of condoms with prostitutes. The contribution of nonbridge clients for spread of HIV into the general population theoretically would be minor as long as they have no steady or occasional partners. Report of STI during the previous 6 months was a significant predictor of bridging behaviour.

\section{DISCUSSION}

This study draws attention to the potential role of clients of brothel prostitutes as a bridge in the transmission of HIV/ AIDS beyond high risk groups. Although HIV rates in Senegal are comparatively lower than in other sub-Saharan African countries, the increasing proportion of women among AIDS patients, as recently observed, highlights the expansion of the

Table 2 Adjusted odds ratio for significant predictors of "bridge" category using logistic regression analysis and two other bridge categories, Senegal 2000

\begin{tabular}{|c|c|c|}
\hline & $\mathrm{OR}^{*}$ & $95 \% \mathrm{Cl}$ \\
\hline \multicolumn{3}{|l|}{ Bridge $v$ potential bridge } \\
\hline Frequent several brothels & $2.17 \dagger$ & 1.42 to 3.32 \\
\hline Always buy sex from different women & $1.97 \dagger$ & 1.26 to 3.10 \\
\hline $\begin{array}{l}\text { Had at least one episode of STD during } \\
\text { previous } 6 \text { months }\end{array}$ & $2.53 \dagger$ & 1.37 to 4.67 \\
\hline \multicolumn{3}{|l|}{ Bridge $v$ non-bridge } \\
\hline No formal education & $0.52 \dagger$ & 0.33 to 0.80 \\
\hline Frequent several brothels & $1.65 \ddagger$ & 1.04 to 2.61 \\
\hline $\begin{array}{l}\text { Not used condoms previous sex contact with } \\
\text { a prostitute }\end{array}$ & $5.29 \dagger$ & 3.35 to 8.36 \\
\hline $\begin{array}{l}\text { Had at least one episode of STI during } \\
\text { previous } 6 \text { months }\end{array}$ & $2.12 \ddagger$ & 1.10 to 4.13 \\
\hline
\end{tabular}


HIV infection from core groups to the general population. Likewise, Lowndes et al reported that unprotected sex with male clients of female prostitutes could account for most of the estimated yearly numbers of HIV infections in Benin among Cotonou women. ${ }^{12}$

The analysis of clients' sexual behaviour is consistent with the hypothesis of bridge formation between prostitutes and women from the general population. Data in this study indicate that HIV seroprevalence in these males, particularly among older clients, is higher than in the general population. Reports of condom use with prostitutes are not negligible but rather inconsistent. In data from this study published elsewhere ${ }^{13}$ condom use was reported to be much lower with steady and occasional partners. The whole analysis suggests that male clients of female prostitutes, acting as a core group and as a bridge, may have an important role in the transmission of HIV/AIDS in Senegal, and that steady and occasional partners of clients are at increasing risk for HIV infection. In addition, differential reports of STIs between bridge and non-bridge clients provide evidence that prostitution is a potential risk factor for STIs and consequently to HIV infection.

\section{CONTRIBUTORS}

MEGES devised the idea for the study, designed the protocol, conducted the field work and the statistical analysis and wrote the first draft of the manuscript; GE advised on the design of the study, advised in the definition of the field procedures; both authors contributed to various drafts of the manuscript.

\section{Authors' affiliations}

M E Gomes do Espirito Santo*, National Service of Great Endemic Diseases, Ministry of Health and Prevention of Senegal, French Cooperation, Dakar, Senegal

G D Etheredge, Department of Epidemiology, Tulane University School of Public Health and Tropical Medicine, New Orleans, LA, USA
*Current affiliation: Department of Environment Health, Institut de Veille Sanitaire, Saint-Maurice, France.

Correspondence to: M E Gomes do Espirito Santo, 9, Boulevard de Magenta, 75010 Paris, France; egomes@noos.fr

Accepted for publication 16 November 2004

\section{REFERENCES}

1 Kitabu M, Maitha G, Mungai J, et al. Trends and seroprevalence of HIV among four population groups in Nairobi in the 1989-1991, VIII International Conference on AIDS/III STD World Congress.Amsterdam, 1992.

2 Hawken MP, Melis RD, Ngombo D, et al. Part time female sex workers in a suburban community in Kenya: a vulnerable hidden population. Sex Transm Infect, 2002;78, 271-3.

3 Rothenberg RB. The geography of gonorrhea. Empirical demonstration of core group transmission. Am J Epidemiol 1983;117:688-94.

4 Voeten HA, Egesah OB, Ondiege My, et al. Clients of female sex workers in Nyanza province, Kenya: a core group in STD/HIV transmission. Sex Transm Dis, 2002;29, 444-52.

5 Senegal Ministry of Health and Prevention, HIV/AIDS Surveillance Program, Epidemiological Bulletin No 9 March 2002.

6 Gomes do Espirito Santo E. Role of clients of prostitutes in the spread of HIV/ AIDS: the case of Senegal-a low prevalence country. DrPH Dissertation for School of Public Health and Tropical Medicine, New Orleans, LA: Tulane University, September, 2000.

7 Robinson NJ, Mulder D, Auvert B, et al. Type of partnership and heterosexual spread of HIV infection in rural Uganda: results from simulation modelling. Int J STD AIDS 1999; 10:718-25.

8 Djomand G, Greenberg AE, Sassan-Morokro M, Tossou O, et al. The epidemic of HIV/AIDS in Abidjan, Cote d'Ivoire: a review of data collected by Projet RETRO-CI from 1987 to 1993. J Acquir Immune Defic Syndr Hum Retrovirol 1995;10:358-65.

9 Potts M, Anderson R, Boily M-C. Slowing the spread of human immunodeficiency virus in developing countries. Lancet, 1991;338, 608-13.

10 MacKellar D, Valleroy L, Karon J, et al. The young men's survey: methods for estimating HIV seroprevalence and risk factors among young men who have sex with men. Pub Health Rep 1996;1:138-44.

11 Kamat HA, Adhia M, Koppikar GV, et al. Detection of antibodies to HIV in saliva. Natl Med J India 1999;12:159-61.

12 Lowndes $\mathrm{CM}$, Alary M, Meda H, et al. Role of core and bridging groups in the transmission dynamics of HIV and STIs in Cotonou, Benin, West Africa. Sex Transm Infect 2002;78(Suppl 1):i69-77.

13 Do Espirito Santo ME, Etheredge GD. HIV prevalence and sexual behaviour of male clients of brothels' prostitutes in Dakar, Senegal. AIDS Care 2003; 15:53-62. 